\title{
葡萄园生态系统碳源/汇及碳减排策略研究进展
}

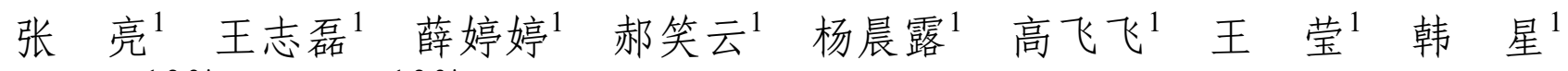 \\ 李 华 $1,2,3^{*}$ 王 华 $1,2,3^{*}$
}

${ }^{1}$ 西北农林科技大学葡萄酒学院, 陕西杨凌 $712100 ;{ }^{2}$ 中国葡萄酒产业技术研究院, 银川 $750000 ;{ }^{3}$ 陕西省葡萄与葡萄酒工程研究中心, 陕西杨凌 712100

摘 要 葡萄园生态系统是农业生态系统的重要组成部分, 集中连片栽培的葡萄园具有重要的生态价值。开展葡萄园生态系 统碳源/汇的研究, 是完整探讨葡萄园生态系统碳循环必不可少的内容。随着葡萄生态学研究的进一步深入, 如何直观地揭示 葡萄园生态系统碳循环规律和碳汇功能已经成为葡萄生态学领域关注的热点问题。研究发现, 葡萄园生态系统固定大量碳, 将碳封存在葡萄果实等一年生器官、主干等多年生器官以及土壤碳库中。葡萄园生态系统碳输入量大于碳输出量, 是碳汇; 土 壤是葡萄园生态系统最大的碳库, 占总碳储量的 $70 \%$, 尤其是土藤界面; 覆盖和免耕作为葡萄园的碳减排策略, 可以减少碳 排放, 提高葡萄园土壤肥力。基于此, 为了阐明葡萄园生态系统的碳汇价值, 该文围绕葡萄生态学最新研究进展, 系统回顾了 葡萄园生态系统中碳循环规律、碳汇研究进展及碳减排策略, 为葡萄生态学的研究提供理论基础, 并对本领域未来的研究方 向和应用前景进行展望。

关键词＼cjkstart葡萄园生态系统; 碳循环; 碳源; 碳汇; 碳储量; 碳减排策略

张亮, 王志否, 薛婷婷, 郝笑云, 杨晨露, 高飞飞, 王䒯, 韩星, 李华, 王华 (2020). 葡萄园生态系统碳源/汇及碳减排策略研究进展. 植物生态学报, 44, 179-191. DOI: $10.17521 /$ cjpe.2019.0252

\section{Progress in studies of carbon source/sink and emission reduction strategies in vineyard eco- system}

ZHANG Liang ${ }^{1}$, WANG Zhi-Lei ${ }^{1}$, XUE Ting-Ting ${ }^{1}$, HAO Xiao-Yun ${ }^{1}$, YANG Chen-Lu ${ }^{1}$, GAO Fei-Fei ${ }^{1}$, WANG Ying ${ }^{1}$, HAN Xing ${ }^{1}$, LI Hua ${ }^{1,2,3^{*}}$, and WANG Hua ${ }^{1,2,3^{*}}$

${ }^{1}$ College of Enology, Northwest A\&F University, Yangling, Shaanxi 712100, China; ${ }^{2}$ Wine Industrial Technology Research Institute of China, Yinchuan 750000, China; and ${ }^{3}$ Shaanxi Engineering Research Center for Viti-Viniculture, Yangling, Shaanxi 712100, China

\section{Abstract}

The vineyard ecosystem is an important part of agro-ecosystem, and contiguous vineyards have important ecological values. The research on carbon source/sink in vineyard ecosystem is an indispensable content of our understanding of carbon cycling. The mechanisms of carbon cycling and the carbon sink function of vineyard ecosystem have become hot topics. We found that a large amount of carbon was fixed in vineyard ecosystem that was distributed in annual organs (fruit, etc), perennial organs (trunk, etc) and soil carbon pool. The carbon input flux of the vineyard ecosystem was greater than the carbon output flux, suggesting a carbon sink. Soil was the largest carbon pool of vineyard ecosystem, accounting for $70 \%$ of total carbon stock, especially the soil-vines interface. Covering and non-tillage can reduce carbon emissions and increase soil fertility in vineyards. In order to clarify the carbon sink functions of vineyard ecosystem, we reviewed the latest research progress in the field, including the mechanisms of carbon cycling, and the strategies of carbon emission reduction. This paper provides a theoretical basis and prospects for future research directions and application.

Key words vineyard ecosystem; carbon cycling; carbon source; carbon sink; carbon stock; carbon reduction strategies

Zhang L, Wang ZL, Xue TT, Hao XY, Yang CL, Gao FF, Wang Y, Han X, Li H, Wang H (2020). Progress in studies of carbon source/sink and emission reduction strategies in vineyard ecosystem. Chinese Journal of Plant Ecology, 44, 179-191. DOI: $10.17521 /$ cjpe. 2019.0252

收稿日期Received: 2019-09-25 接受日期Accepted: 2020-01-08

基金项目: 国家林业和草原局林业科技成果推广项目(K3130217005)和国家重点研发计划(2019YFD1002500)。Supported by the Science and Technology Achievements Promotion Program of National Forestry and Grassland Administration (K3130217005), and the National Key R\&D Program of China (2019YFD1002500).

* 通信作者Corresponding author (Li H: lihuawine@nwsuaf.edu.cn; Wang H: wanghua@nwsuaf.edu.cn) 
大气中 $\mathrm{CO}_{2}$ 含量增加造成的温室效应，导致海 平面上升、水资源分布不均等一系列环境问题, 碳 循环问题引起了学术界的广泛关注。在当前气候变 化背景下，应运而生的节能减排、农业生态系统的 碳源、碳汇和固碳等问题成为科学界研究的热点 (Walther et al., 2002; Buermann et al., 2007; Goosse, 2010; Vendrame et al., 2019)。果园作为经济林的代 表, 是农业生态系统的重要组成部分。果园生态系 统与草原生态系统相比, 单位面积碳固定量更高 (Janssens et al., 2003), 与非经济林生态系统相比, 人为可控性更大。通过合理施肥、覆盖作物、免耕、 农艺措施等管理方式可以改善土壤结构, 提高果园 生产力, 从而实现生态系统碳减排与增效的双赢。

葡萄(Vitis vinifera)在我国广泛栽培, 已成为重 要的果树经济作物, 在农业经济中占有重要地位。 2015 年, 我国葡萄种植面积为 77.01 万 $\mathrm{hm}^{2}$, 占全球 种植面积的 $10.8 \%$ (田野等, 2018), 目前我国葡萄产 区主要分布在天山脚下、河西走廊、宁夏中部、黄 土高原中北部、山西、内蒙古、河北大部分地区以 及山东大部分地区(王蕾等, 2017), 研究葡萄的生态 价值具有重要意义。

葡萄通过光合作用固定大气中的 $\mathrm{CO}_{2}$, 可通过地 表凋落物、细根周转和根系分泌物将光合产物分泌 到土壤中, 又通过自身呼吸作用、土壤呼吸等过程 释放 $\mathrm{CO}_{2}$ 。由于葡萄园生态系统是一个有机碳储存 的巨大库, 其较小幅度的变动可能影响到碳向大气 的排放(Bates et al., 2002)。更为重要的是, 葡萄园生 态系统在产出果品的同时, 还起到重要的碳封存和 碳汇功能(Dobrei et al., 2015)。在新西兰的葡萄园进 行的研究发现, 地上部分生物量为 $6.2 \mathrm{t} \cdot \mathrm{hm}^{-2}(30 \%$ 叶, $24 \%$ 枝条, $40 \%$ 果实), 相当于碳储量为 $9.1 \mathrm{t} \cdot \mathrm{hm}^{-2}$ (Colman \& Päster, 2007)。与果园和乔木种植园相类 似, 葡萄作为多年生藤本作物, 它拥有永久性的木 质结构, 将碳长期封存在木质组织中, 有助于减少 温室气体 $(\mathrm{GHG})$ 的排放。另外, 葡萄在同一块土地 上数十年不受干扰, 修剪产生的枝条, 覆盖到葡萄 种植行内, 增加土壤碳储量(Williams et al., 2011)。

已有学者对葡萄生态学做了大量的研究, 在葡 萄园生态系统的固碳和碳汇研究方面取得了一定成 果。在甘肃、陕西等地, 研究红地球(Vitis vinifera 'Red Globe')、巨峰(Vitis vinifera $\times$ Vitis labrusca) 葡 萄品种的光合特性, 发现光合速率与光照强度、 $\mathrm{CO}_{2}$
浓度、水分有效性有关, 并且不同品种对 $\mathrm{CO}_{2}$ 的固定 能力是不同的(严巧娣和苏培坌, 2005; 房玉林等, 2006)。利用浴度相关技术研究葡萄园生态系统 $\mathrm{CO}_{2}$ 净交换量 $(N E E)$, 发现葡萄园夜间和黎明 $N E E$ 基本 为正值, 此时葡萄园主要进行呼吸作用, 为碳源; 日出后葡萄园 $N E E$ 为负值, 转变为碳汇, 随光照强 度增加, 碳汇强度逐渐增大, 并且天气条件显著影 响葡萄园 $N E E$ 的日变化(郭维华和高云, 2013)。

鉴于此, 为了阐明葡萄园生态系统的碳汇价值, 本文拟围绕葡萄园生态系统中 $\mathrm{CO}_{2}$ 产生、碳储量和 碳通量等方面的研究成果进行综述, 以期为揭示葡 萄园生态系统的生态功能提供理论依据。

\section{1 葡萄园生态系统碳循环规律}

葡萄园生态系统属于源还是汇, 主要取决于碳 输入和碳输出两个对立过程(图1)。碳输入主要是葡 萄通过光合作用实现, 碳输出途径有葡萄的自养呼 吸、土壤动物的异养呼吸以及调落物的矿化作用等 (Kroodsma \& Field, 2006)。此外, 葡萄浆果采收、整 形修剪、行间生草等管理措施都会对葡萄园生态系 统碳循环产生一定影响。

葡萄园生态系统碳循环规律如图2所示, 通过 葡萄固定 $\mathrm{CO}_{2}$ 产生光合产物, 组成葡萄生物量; 土 壤碳库经过土壤呼吸等释放 $\mathrm{CO}_{2}$, 也有人为等因素 释放 $\mathrm{CO}_{2}$ 。通过光合作用固定的光合产物, 表示进入 葡萄园生态系统的初始物质, 称为总初级生产力 $(G P P)$ 。GPP除去葡萄自身呼吸作用消耗 $\left(R_{\mathrm{a}}\right)$ 的剩余 部分, 称为净初级生产力 $(N P P), N P P$ 反映了固定和 转化光合产物的效率, 用公式表示为: $N P P=G P P-$ $R_{\mathrm{a}}$ 。NPP除去异养生物呼吸消耗 $\left(R_{\mathrm{h}}\right.$, 土壤呼吸 $)$ 的剩 余部分, 称为净生态系统生产力 $(N E P)$, 公式表示为 $N E P=N P P-R_{\mathrm{h}}$ 。 $N E P$ 减去各类自然和人为干扰等 非生物呼吸消耗 $(N R)$, 剩余的部分为净葡萄园生物 群区生产力 $(N B P)$, 公式表示为 $N B P=N E P-N R$ 。

\section{2 葡萄园生态系统碳汇研究}

碳汇指生态系统吸收、储存 $\mathrm{CO}_{2}$ 的多少, 或者说 是生态系统吸收、储存 $\mathrm{CO}_{2}$ 的能力 (West \& Marland, 2002; Smith et al., 2004)。碳通量是对碳汇的动态 (周期性)描述, 碳储量是对碳汇的静态描述, 下文 从碳通量和碳储量两个方面来论述葡萄园生态系 统的碳汇研究。 


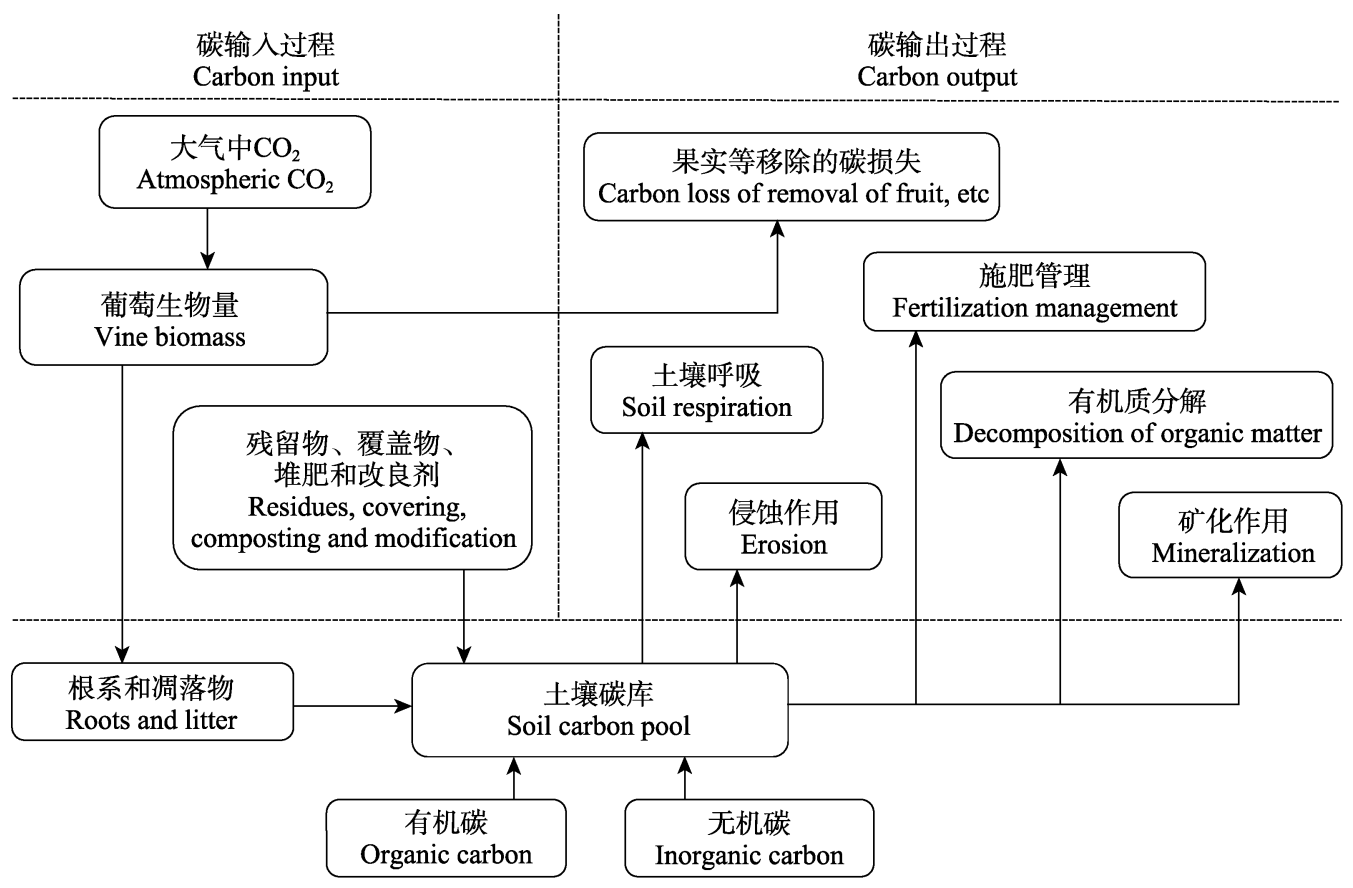

图1 葡萄园生态系统碳输入和输出过程。

Fig. 1 Carbon input and output processes in vineyard ecosystem.

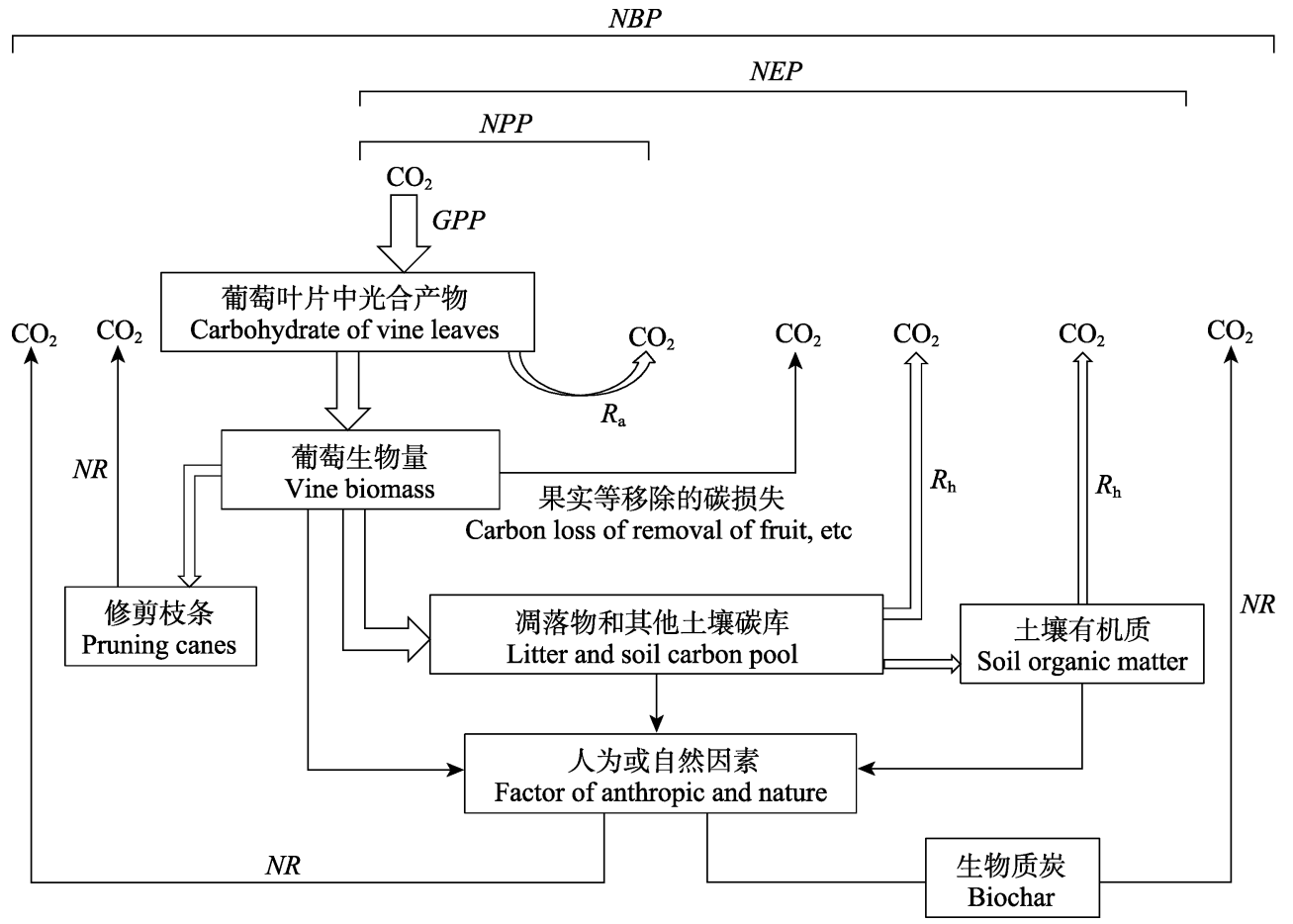

图2 葡萄园生态系统碳循环规律。箭头方向表示碳流向。GPP, 总初级生产力; $N B P$, 净葡萄园生物群生产力; $N E P$, 净葡萄园 生态系统生产力; $N P P$, 葡萄净初级生产力; $N R$, 非生物呼吸消耗; $R_{\mathrm{a}}$, 葡萄自养呼吸作用; $R_{\mathrm{h}}$, 土壤呼吸。

Fig. 2 Carbon cycling in vineyard ecosystem. The arrow indicates direction of carbon flow. GPP, gross primary productivity; $N B P$, net productivity in vineyard biota; $N E P$, net productivity in vineyard ecosystem; $N P P$, net primary productivity in vines; $N R$, non-biological respiration consumption; $R_{\mathrm{a}}$, autotrophic respiration of vines; $R_{\mathrm{h}}$, soil respiration.

\section{1 葡萄园生态系统碳通量}

碳通量表示生态系统中单位时间通过单位地表 面积的某一特定组分碳的量, 可利用浴度相关技术
对葡萄园生态系统碳通量进行观测。NEE是生态系 统吸收与释放 $\mathrm{CO}_{2}$ 的差值, 该值为正表明向大气中 释放 $\mathrm{CO}_{2}$, 为负则表示吸收 $\mathrm{CO}_{2}$, 是衡量植被下垫面 
对大气碳库源汇作用的标准(杨剑锋等, 2018)。

葡萄园生态系统 NEE 呈明显的季节变化规律, 生育初期 NEE为正值, 表现为弱的碳源, 生育中期 为明显碳汇功能, 生育末期碳汇能力开始下降, 其 他物候期为碳源。在年生长周期中, 葡萄园生态系 统为碳汇功能。如, Tezza等(2019)采用浴度相关方法, 研究意大利东北地区葡萄园生态系统从2015至2016 年的碳通量, 观测结束发现葡萄园生态系统为净碳 汇, 吸收 $\mathrm{CO}_{2}$ 量为 $233 \mathrm{~g} \cdot \mathrm{m}^{-2}$ 。在我国, 葡萄园在生长 季(5-9月)是一个净碳汇, 7和 8 月的 NEE 最大, 研究 发现2008、2009和2010年葡萄园生态系统NEE分别为 $-820 、-824$ 和 $-961 \mathrm{~g} \cdot \mathrm{m}^{-2}$, 均为碳汇 (Guo et al., 2014)。国内外研究得出的葡萄园生态系统NEE相差 较大, 可能原因为研究地点和研究时间不同, 生态 条件差异明显, 因此得出不同的研究结果。另外, 应 用浴度相关技术研究不同条件下葡萄园 NEE的典型 日和生育期变化规律, 结果证实葡萄园 NEE 晴天日 变化呈“W”形曲线, 阴天呈“U”形曲线; 灌水和剪枝 后不影响 NEE日变化曲线形状, 但灌水后峰谷值之 差明显小于灌水前, 剪枝会减小碳汇(郭维华和高 云, 2013), 由于午间会出现光合午休现象, 所以葡 萄园NEE日变化规律呈双峰形曲线。

\section{2 葡萄园生态系统碳储量}

葡萄园生态系统是一个巨大的碳库, 量化其碳 储存的方法, 当前主要有生物量统计法、涡流协方 差法、碳足迹法和异速方程法(Kuyah et al., 2012)。

葡萄园生态系统中, 碳可以短期储存于一年生 器官(叶、果实和一年生枝条), 长期储存于根、主蔓 和主干等多年生器官, 或储存于土壤碳库。在整个
葡萄园中, $30 \%$ 的碳封存在葡萄植株生物量中, 其 他70\%储存在土壤中(Longbottom \& Petrie, 2015)。 葡萄园生态系统的碳储量, 包括生物量碳储量和土 壤碳储量(图3)。葡萄园总碳储量为生物量碳储量和 土壤碳储量之和, 总碳储量与种植年限、葡萄品种等 有关。研究发现, 美国加利福尼亚州葡萄园总碳储 量为 $87.10 \mathrm{t} \cdot \mathrm{hm}^{-2}$ (Williams et al., 2011)。Chiarawipa 等(2013)研究我国3个葡萄园的碳储量, 发现18年生 的葡萄园总碳储量为 $77.04 \mathrm{t} \cdot \mathrm{hm}^{-2}, 10$ 年生和 5 年生 的葡萄园总碳储量分别为 66.92 和55.41 $\mathrm{t} \cdot \mathrm{hm}^{-2}$ 。不同 品种葡萄园的总碳储量最高的是赤霞珠(Vitis vinifera 'Cabernet Sauvignon')葡萄园, 为42.75 $\mathrm{t} \cdot \mathrm{hm}^{-2}$; 最低的是霞多丽(Vitis vinifera 'Chardonnay')葡萄园, 为 $8.02 \mathrm{t} \cdot \mathrm{hm}^{-2}$ (Wolff et al., 2018)。

\subsection{1葡萄园生态系统中的生物量碳储量}

葡萄园中生物量碳储量较高, 不同研究之间得 出的结果不尽相同。研究发现, 葡萄园的 NPP或总 生物量碳储量范围为 5.5-11.0 $\mathrm{t} \cdot \mathrm{hm}^{-2}$ (Fidelibus, 2014)。在美国加利福尼亚州葡萄园收集了一些现存 生物量和移除葡萄的生物量, 其碳储量分别为 $1.0-1.3$ 和0.2-0.4 $\mathrm{t} \cdot \mathrm{hm}^{-2}$ (Kroodsma \& Field, 2006)。 对加利福尼亚州北部葡萄园地上的碳储量进行评估, 研究得出碳储量为 $3.0 \mathrm{t} \cdot \mathrm{hm}^{-2}$ (Williams et al., 2011)。 许多研究量化了生物量碳储量, 那么影响生物量碳 储量的因素有哪些? 生物量大小、栽培技术、树龄、 品种等都会影响生物量碳储量。

生物量不同, 碳储量不同。葡萄园中叶和枝条 的生物量为4.0-5.0和5.0-6.0 $\mathrm{t} \cdot \mathrm{hm}^{-2}$, 葡萄园生物量 碳储量为 $18-22 \mathrm{t} \cdot \mathrm{hm}^{-2}$ (Nistor et al., 2018)。相类似的

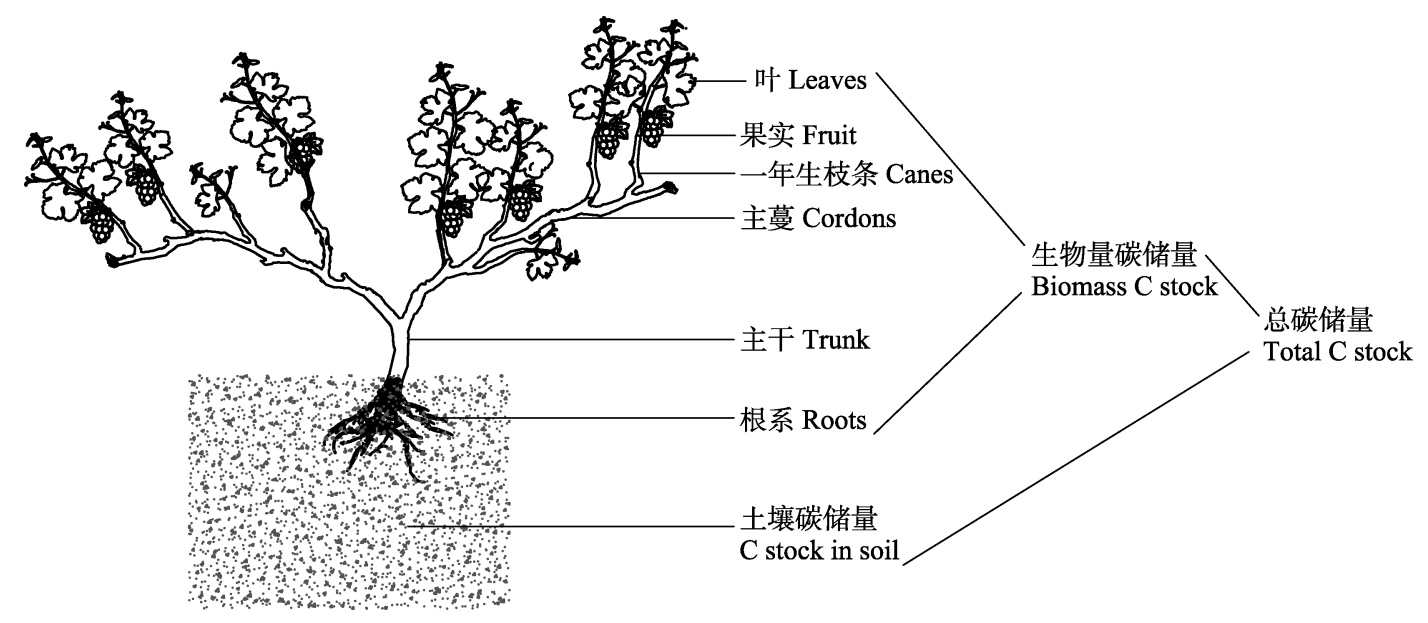

图3 葡萄的结构组成及模拟葡萄园生态系统碳储量分布。

Fig. 3 Composition of vines and simulation of carbon stock in vineyard ecosystem.

www.plant-ecology.com 
研究, 新西兰葡萄园 $4.0 \mathrm{t} \cdot \mathrm{hm}^{-2}$ 生物量所对应的碳储 量为 $8.0 \mathrm{t} \cdot \mathrm{hm}^{-2}$ (Nendel \& Kersebaum, 2004), 究其原 因可能为栽培方式、环境、品种、施肥等影响葡萄 光合作用, 从而影响碳分配, 继而影响葡萄地上部 分碳储量。葡萄树龄也影响碳储量。Chiarawipa等 (2013)对我国3个葡萄园的碳储量进行专项研究, 得 出 10 年生的葡萄园生物量碳储量最高 $\left(48.62 \mathrm{t} \cdot \mathrm{hm}^{-2}\right)$, 其次是 5 年生的葡萄园 $\left(48.46 \mathrm{t} \cdot \mathrm{hm}^{-2}\right), 18$ 年生的葡萄 园最低 $\left(38.72 \mathrm{t} \cdot \mathrm{hm}^{-2}\right)$ 。研究发现, 2009年赤霞珠葡萄 园生物量碳储量为 $3.43 \mathrm{t} \cdot \mathrm{hm}^{-2}, 2010$ 年生物量碳储 量为 $3.55 \mathrm{t} \cdot \mathrm{hm}^{-2}$ (Wolff et al., 2018)。不同品种碳储量 差异显著, 一般情况下红葡萄品种的碳储量高于白 葡萄品种。在澳大利亚葡萄园, 研究 4 个白葡萄和 4 个红葡萄品种的碳储量, 发现每株葡萄的碳储量分 别为: 赤霞珠 $(3.11 \mathrm{~kg})>$ 西拉 (Vitis vinifera 'Syrah', $2.52 \mathrm{~kg})>$ 霞多丽 $(2.04 \mathrm{~kg})>$ 长相思(Vitis vinifera 'Sauvignon Blanc', $1.92 \mathrm{~kg}$ ) >美乐(Vitis vinifera 'Merlot', $1.9 \mathrm{~kg}$ ) >雷司令(Vitis vinifera 'Riesling', $1.44 \mathrm{~kg}$ ) >黑皮诺(Vitis vinifera 'Pinot Noir', $1.27 \mathrm{~kg}$ ) >灰皮诺(Vitis vinifera 'Pinot Gris', 0.78 kg)(Wightwick et al., 2013)。

进一步的研究发现, 在生长季节, 葡萄果实含 有最高浓度的碳，成熟的葡萄可以将 $35 \%-50 \%$ 的光 合产物分配给当年的浆果, 且葡萄园平均将 $1 / 3$ 的 NPP分配给浆果等部分(Mosier et al., 2005), 但对葡 萄不同器官中碳储量知之甚少。也有研究量化了葡 萄不同器官中的碳储量, 各器官中碳储量相差显著 (表1)。单株葡萄的碳分配也进行了研究, 果实占葡 萄碳储量的 $10 \%$, 其中 $26 \%$ 通过皮和种子归还到土 壤, 增加了土壤中的碳储量, 因而生物量碳来源有
助于葡萄园生态系统长期碳储存(Kroodsma \& Field, 2006)。

葡萄的深根系有助于碳封存, 根系碳储量较高 (Bauerle et al., 2008)。研究发现, 根系碳储量为4.1 $\mathrm{t} \cdot \mathrm{hm}^{-2}$, 占葡萄总碳储量的 $33 \%$, 且葡萄地下根系碳 储量主要储存于大于 $6 \mathrm{~mm}$ 的根系中(Morandé et al., 2017)。Brunori等(2016)在不同种植区(天然葡萄种植 区和城市周边葡萄种植区), 采用不同栽培方式(传 统种植方式和有机种植方式)研究根系碳储量, 发 现城市周边葡萄种植区的根系碳储量 $\left(1.70 \mathrm{t} \cdot \mathrm{hm}^{-2}\right)$ 高于天然葡萄种植区的根系碳储量 $\left(0.75 \mathrm{t} \cdot \mathrm{hm}^{-2}\right)$; 在天然葡萄种植区, 传统种植方式的根系碳储 量 $\left(0.75 \mathrm{t} \cdot \mathrm{hm}^{-2}\right)$ 高于有机种植方式的根系碳储量 $\left(0.46 \mathrm{t} \cdot \mathrm{hm}^{-2}\right)$ 。

\subsection{2 葡萄园生态系统中的土壤碳储量}

葡萄园碳储量的研究大多集中在土壤碳汇方 面, 葡萄园生态系统中最大碳储量分布于土壤, 尤 其是土壤表层的土藤界面(Williams et al., 2011; Eldon \& Gershenson, 2015), 并且土壤有机碳(SOC)可 以长期封存在土壤碳库中来抵消大气中 $\mathrm{CO}_{2}$ 的增加 (Lal, 2004; Paradelo et al., 2011)。对葡萄园土壤碳储 量的研究结果证实管理措施对土藤界面的碳储量和 封存潜力影响较大(Novara et al., 2019), 葡萄园的 多种管理措施可以增加土壤中的碳含量, 如营养 保留、覆盖和侵蚀控制等有机管理措施(Agnelli et al., 2014)。Wolff等(2018)采用了3种不同的管理方式 (最小化耕作、间作作物耕作和传统耕作), 研究美国 纳帕谷赤霞珠葡萄园土壤碳储量变化, 发现19912003年间，传统耕作土壤中的碳含量保持不变; 2003-2010年间，最小化耕作方式土壤碳含量平均

表1 葡萄不同器官生物量碳储量分布

Table 1 Distribution of biomass carbon stock in different organs of vines

\begin{tabular}{|c|c|c|c|c|c|}
\hline & $\begin{array}{l}\text { 葡萄器官 } \\
\text { Vine organs }\end{array}$ & $\begin{array}{c}\text { 碳储量 } \\
\text { Carbon stock } \\
\left(\mathrm{t} \cdot \mathrm{hm}^{-2}\right)\end{array}$ & $\begin{array}{l}\text { 碳去向 } \\
\text { Carbon distribution }\end{array}$ & $\begin{array}{c}\text { 总碳储量 } \\
\text { Total carbon stock } \\
\left(\mathrm{t} \cdot \mathrm{hm}^{-2}\right)\end{array}$ & $\begin{array}{c}\text { 比重 } \\
\text { Proportion }(\%)\end{array}$ \\
\hline \multirow[t]{3}{*}{$\begin{array}{l}\text { 一年生器官 } \\
\text { Annual organs }\end{array}$} & 果实 Fruit & 1.7 & $\begin{array}{l}26 \% \text { 碳通过皮和种子回归土壤 } \\
26 \% \text { carbon return to soil through skin and seeds }\end{array}$ & 3.4 & 28 \\
\hline & 叶 Leaves & 0.6 & $\begin{array}{l}100 \% \text { 碳通过凋落回归土壤 } \\
100 \% \text { carbon return to soil by litter }\end{array}$ & & \\
\hline & 一年生枝 Canes & 1.1 & $\begin{array}{l}50 \% \text { 碳分配给当年浆果 } \\
50 \% \text { carbon allocated to berries }\end{array}$ & & \\
\hline \multirow[t]{2}{*}{$\begin{array}{l}\text { 多年生器官 } \\
\text { Perennial organs }\end{array}$} & $\begin{array}{l}\text { 主干和主蔓 } \\
\text { Trunk and cordons }\end{array}$ & 4.8 & $\begin{array}{l}35 \%-50 \% \text { 碳分配给当年浆果 } \\
35 \%-50 \% \text { carbon allocated to berries }\end{array}$ & 8.9 & 72 \\
\hline & 根 Roots & 4.1 & $\begin{array}{l}\text { 部分碳分泌到土壤中 } \\
\text { Part of carbon secreted into soil }\end{array}$ & & \\
\hline
\end{tabular}


增加了 $8.4 \%$, 间作作物耕作方式土壤碳储量表现出 较低的增长, 传统耕作方式土壤碳储量基本保持 不变。

葡萄园中土壤总碳储量很高, Williams等(2011) 对美国加利福尼亚州北部葡萄园土壤的碳储量进行 了评估, 土壤碳储量为 $84.1 \mathrm{t} \cdot \mathrm{hm}^{-2}$ 。一般情况为随着 土壤深度增加土壤碳储量减小, 在新西兰马尔伯勒 地区 15 年生的葡萄园, $0-0.15 \mathrm{~m}$ 深的土壤碳储量为 (12 \pm 5$) \mathrm{t} \cdot \mathrm{hm}^{-2}, 0.15 \mathrm{~m}$ 以下土层中碳储量低于 $(12 \pm$ 5) $t \cdot \mathrm{hm}^{-2}$ (Deurer et al., 2012)。而且一些管理因素显 著影响葡萄园土壤碳储量。将管理过程中修剪的枝 条、枯死的藤蔓、疏花、疏叶作为有机质并入土壤 中进行碳封存, 增加了SOC的储量; 有机肥(粪肥、 农作物残体、秸秆、废弃物)和覆盖物也增加了SOC 的储量(Lal, 2004)。然而, 有研究发现覆盖物对土壤 碳储量影响不显著。有覆盖物土壤碳储量为(63.5 土 13.5) $\mathrm{t} \cdot \mathrm{hm}^{-2}$, 无覆盖物土壤碳储量为 $(49.5 \pm 3.5)$ $\mathrm{t} \cdot \mathrm{hm}^{-2}$, 二者没有显著性差异(Deurer et al., 2012), 究其原因为在堆肥、覆盖作物或草本植物调落后,
土壤中碳储量需要多年才能增加(Longbottom \& Petrie, 2015)。Powlson等(2011)在温带气候地区研究 土壤碳储量, 发现从植物生物量融入土壤 1 年后, 只 有大约 $1 / 3$ SOC被保留下来。

葡萄园生态系统中土壤是一个巨大的碳库, 更 多土壤碳储量有利于改善土壤肥力、结构和物理性 质, 增加微生物活性和持水能力 (Ludwig et al., 2011)。土壤碳储量取决于土壤类型、气候(主要是 降水和温度)、土地管理和植被, 可以通过施用肥 料、堆肥或植物残体分解等改善碳储量(Williams et al., 2011)。此外, 有研究证实酿酒过程中产生的一 部分碳返回土壤中，并被长期储存，同样说明了葡 萄园生态系统的土壤是一个巨大的碳库(Novara et al., 2019)。

\subsection{3 葡萄园生态系统碳储量的影响因素}

要达到优质、稳产、长寿、美观的可持续发展 目标，葡萄园需要多种栽培技术，其中一些管理技 术对葡萄园生态系统中的碳水平有显著的影响(表 2)。研究发现，农艺措施和田间管理技术都会显著

表2 不同管理技术对葡萄园生态系统碳储量的影响机理

Table 2 Mechanisms of the effects of management technology on carbon stock in vineyard ecosystem

\begin{tabular}{|c|c|c|c|}
\hline $\begin{array}{l}\text { 管理技术 } \\
\text { Management technology }\end{array}$ & 措施 Measures & 碳储量变化 Change of carbon stock & 控制机理 Mechanisms \\
\hline \multirow[t]{7}{*}{$\begin{array}{l}\text { 农艺措施 } \\
\text { Agronomic measures }\end{array}$} & 耕作 Tillage & 免耕>耕作 Non-tillage $>$ tillage & $\begin{array}{l}\text { 干预越小, 系统碳分解越少 } \\
\text { Reduce intervention, reduce carbon decomposition of } \\
\text { ecosystem }\end{array}$ \\
\hline & 施肥 Fertilization & 碳储量增加 Carbon stock increase & 增加土壤有机质 Increase soil organic matter \\
\hline & 喷药 Pesticide & 碳储量降低 Carbon stock decrease & $\begin{array}{l}\text { 增加干预和降低土壤活性 } \\
\text { Increase intervention and reduce soil activity }\end{array}$ \\
\hline & 灌溉 Irrigation & 碳储量降低 Carbon stock decrease & $\begin{array}{l}\text { 增加生态系统的人为干预 } \\
\text { Increase human intervention in ecosystem }\end{array}$ \\
\hline & 修剪 Pruning & 碳储量增加 Carbon stock increase & 增加土壤有机质 Increase soil organic matter \\
\hline & 收割 Harvest & 碳储量增加 Carbon stock increase & 增加土壤有机质 Increase soil organic matter \\
\hline & $\begin{array}{l}\text { 种植方式 } \\
\text { Establishment method }\end{array}$ & $\begin{array}{l}\text { 常规葡萄园碳储量低于有机葡萄园 } \\
\text { Carbon stock of conventional vineyard lower than } \\
\text { organic vineyard }\end{array}$ & $\begin{array}{l}\text { 有机葡萄园免耕土壤储存更多有机质 } \\
\text { Organic vineyard increases organic matter in non- } \\
\text { tillage soil }\end{array}$ \\
\hline \multirow[t]{4}{*}{$\begin{array}{l}\text { 田间管理 } \\
\text { Farmland management }\end{array}$} & $\begin{array}{l}\text { 复种 } \\
\text { Multiple cropping }\end{array}$ & 碳储量增加 Carbon stock increase & 增加土壤有机质 Increase soil organic matter \\
\hline & 覆盖 Covering & 碳储量增加 Carbon stock increase & 增加土壤有机质 Increase soil organic matter \\
\hline & 轮作 Rotation & 碳储量增加 Carbon stock increase & 增加土壤有机质 Increase soil organic matter \\
\hline & 运输 Transport & 碳储量降低 Carbon stock decrease & $\begin{array}{l}\text { 增加生态系统的人为干预 } \\
\text { Increase human intervention in ecosystem }\end{array}$ \\
\hline \multirow[t]{5}{*}{ 其他因素 Other factors } & 区域 Region & $\begin{array}{l}\text { 不同区域碳储量不同 } \\
\text { Different carbon stock in region }\end{array}$ & $\begin{array}{l}\text { 不同区域的气候和土壤质地不同 } \\
\text { Different climates and soil textures in region }\end{array}$ \\
\hline & 品种 Variety & $\begin{array}{l}\text { 红葡萄品种碳储量高于白葡萄品种 } \\
\text { Red variety of carbon stock higher than white variety }\end{array}$ & $\begin{array}{l}\text { 不同葡萄品种的生物特性不同 } \\
\text { Different biological characteristics of variety }\end{array}$ \\
\hline & 树龄 Age & $\begin{array}{l}\text { 树龄越大植株碳储量越高 } \\
\text { The more carbon stock in the older }\end{array}$ & $\begin{array}{l}\text { 葡萄作为碳汇, 逐年积累 } \\
\text { Accumulation of vine year by year, as carbon sink }\end{array}$ \\
\hline & $\begin{array}{l}\text { 生长季 } \\
\text { Growing season }\end{array}$ & $\begin{array}{l}\text { 植株生长季碳储量最高 } \\
\text { The most carbon stock in growing season }\end{array}$ & 生长季是一个净碳汇 A net carbon sink \\
\hline & 温度 Temperature & $\begin{array}{l}\text { 温度越高碳储量越低 } \\
\text { The higher temperature, the lower carbon stock }\end{array}$ & $\begin{array}{l}\text { 温度越高土壤有机质分解越快 } \\
\text { The higher temperature, the faster decomposition of soil } \\
\text { organic matter }\end{array}$ \\
\hline
\end{tabular}


影响葡萄生物量, 从而影响葡萄园生态系统碳储量 (Novara et al., 2011)。Brunori等(2016)采用主成分分 析, 研究葡萄园生态系统的碳汇功能, 结果证实土 壤的物理特性、葡萄的生物学特性和葡萄园的管理 技术(有机和常规耕作), 都是影响 $\mathrm{C}$ 储量的主要因 素。

2.2.3.1 农艺措施 关于多年生作物系统中农艺措 施对碳储量影响的研究相对较少, 但有关葡萄园生 态系统中农艺措施对碳储量的影响研究有了一定的 进展。研究发现, 在葡萄园使用杀虫剂、化肥和农 药是葡萄酒产业链中 GHG排放的主要来源, 也会影 响碳储量(Pizzigallo et al., 2008; Fusi et al., 2014)。种 植方式显著地影响葡萄园碳储量。在天然葡萄种植 区，传统葡萄园的碳储量远高于有机葡萄园的碳储 量 $(0-60 \mathrm{~cm}$ 深土层, 传统葡萄园碳储量为 241.79 $\mathrm{t} \cdot \mathrm{hm}^{-2}$, 有机葡萄园碳储量为 $161.41 \mathrm{t} \cdot \mathrm{hm}^{-2}$ ), 原因为 有机葡萄园的土壤呼吸速率高于常规土壤呼吸速率 (Liguori et al., 2009; Brunori et al., 2016), 这与大多 数研究结果相反。

其他一些农艺措施也会影响葡萄园碳储量(表 2)。研究发现, 灌溉会促进微生物对SOC的分解, 降 低土壤中SOC的水平(Tesic et al., 2007)。冠层管理技 术可能是改善葡萄园碳汇功能的一个有价值的手段, 夏季修剪改变了叶幕间光透性、叶片结构和碳水化 合物分配，增强了碳汇作用。修剪和收割是一个将 碳封存到葡萄园土壤中的手段, 大部分修剪后的植 物生物量、酿酒后的皮渣留在葡萄园里, 对土壤中 的碳库有贡献, 提升了SOC含量(Morlat \& Chaussod, 2008); 另一项研究表明修剪对碳储量没有显著性 影响(Lejon et al., 2007)。最后得出的结论是, 葡萄园 修剪物进行堆肥或转化为生物炭, 并仔细考虑操作 过程中的碳平衡, 否则不予鼓励, 而且副产物皮渣 为堆肥、生物炭或其他土壤改良提供了潜在的原料。

2.2.3.2 田间管理 葡萄园的田间管理技术会影响 整个葡萄生态系统的碳储量, 增强葡萄园缓解气候 变化的能力, 田间管理技术包括覆盖、复种和轮作 等技术(表2)。田间管理技术的复种和轮作对葡萄园 碳储量起重要作用(表2)。

葡萄园田间管理技术中，覆盖对其碳储量影响 最为显著, 将在下文的碳减排策略中进行详细综 述。葡萄园生态系统中的覆盖管理, 主要有生草覆 盖和作物覆盖。葡萄园生草覆盖, 改善了葡萄园小
气候, 有利于葡萄树冠快速生长, 最大程度增加碳 的吸收, 提高葡萄园中土壤的碳含量(Govaerts et al., 2009)。作物覆盖同样重要。地中海地区的葡萄园生 态系统中, 覆盖作物可能会增加土壤中碳的输入, 导致土壤中的 SOC 随着时间的延长而增加(Basche et al., 2014; Novara et al., 2019)。另外, 葡萄园的覆 盖管理可以被认为是耕地和草地系统的结合, 在每 行之间种植永久性和半永久性的覆盖物, 类似于免 耕, 而且从耕地系统到草地系统的转换通常会导致 碳吸收的增加(Tesic et al., 2007; Celette et al., 2008), 在较少耕作和覆盖作物的管理条件下, 表层土壤碳 储量水平显著增加。

2.2.3.3 其他因素 除了以上因素影响葡萄园碳储 量, 其他一些因素也显著地影响葡萄园生态系统碳 储量(表2)。有研究发现, 不同土地用途、土地植被 类型之间的转耕对土壤碳含量有极显著的影响 (Post \& Kwon, 2000; Houghton \& Goodale, 2004)。

土壤作为一个潜在的碳源, 自然植被转耕释放 $20 \%-70 \%$ 的土壤碳储量(Luo et al., 2010), 而且SOC 对土地利用极为敏感(Chen et al., 2018), 以地中海 的葡萄园为例, 在地中海的草原地区建立葡萄园 21 年后，土壤表层 $15 \mathrm{~cm}$ 处的SOC下降了 $57 \%$ (Novara et al., 2013)。栽培类型对土壤的碳储存也有重要的 影响，最小灌溉和免耕条件下，有机栽培葡萄园 $\mathrm{SOC}$ 的损失比传统栽培葡萄园更小, 有机栽培的葡 萄园生态系统具有将碳封存到土壤中的巨大潜力 (Jastrow et al., 2007; DuPont et al., 2010)。葡萄园生 态系统的碳储量还受地域、树龄和品种的影响, 所 以研究葡萄园生态系统碳储量是一个系统、复杂的 过程。

气候等生态因素对葡萄园碳储量有显著的影响 作用(表2)。气候和水分有效性是影响葡萄园生态系 统碳储量的主要因素。碳储量随年份变化较大, 主 要归因于气候条件的影响, 在干燥的气候条件下碳 储量明显降低。有研究结果证实, 当水不是限制因 素时葡萄园的碳储量可以达到一个相对较高的值 (Novara et al., 2019)。

\section{3 葡萄园生态系统中 $\mathrm{CO}_{2}$ 产生及碳减排策略}

\section{1 $\mathrm{CO}_{2}$ 的产生}

葡萄园生态系统的碳输出过程主要指葡萄园土 壤呼吸过程, 以及调落物的矿质过程。即使葡萄种 
植比其他农业生产的污染更少, 葡萄种植必须采取 措施来减少GHG的排放(Nistor et al., 2018)。然而, 很少有研究关注葡萄园在 $\mathrm{GHG}$ 产生和碳封存中的 作用, 因为研究葡萄园在 $G H G$ 排放方面的作用需要 相当长的时间, 研究产生 $\mathrm{N}_{2} \mathrm{O}$ 和 $\mathrm{CH}_{4}$ 的影响因素需 要3-5年, 研究碳固定的长期管理措施需要10-20年 (Yu et al., 2017)。

葡萄园生态系统到底产生多少 $\mathrm{CO}_{2}$ ? 研究者通 过碳足迹这一概念进行了说明。在意大利撒丁岛南 部的葡萄园进行了碳足迹调查研究, 发现每生产 1 $\mathrm{kg}$ 葡萄, 会释放0.39 $\mathrm{kg} \mathrm{CO}_{2}$ (Marras et al., 2015)。从 葡萄栽培和葡萄种植来看, 各研究得出的碳足迹结 果不相同。Chiriacò等(2019)得出葡萄栽培过程中的 碳足迹为 $15 \%$, Soosay等(2012)得出葡萄栽培过程中 的碳足迹为 $28 \%$ 。通过研究葡萄酒产业的碳足迹, 发现葡萄酒生产过程的碳足迹远远高于葡萄栽培过 程的碳足迹。葡萄酒加工和包装过程的碳足迹最高, 为 $22 \%$, 葡萄生长阶段的碳足迹为 $18 \%$ (Rugani et al., 2013)。Bosco等(2011)对意大利葡萄园的研究发 现, 葡萄生长阶段的碳足迹仅为 $7 \%$ 。不同研究者得 出碳足迹水平不一致, 其原因可能为不同的葡萄酒 生产阶段和环境条件在各研究之间存在很大的差 异。

葡萄园生态系统中, 除土壤异养呼吸过程和调 落物的矿化过程排放 $\mathrm{CO}_{2}$ 之外, 栽培过程中也产生 大量的 $\mathrm{CO}_{2}$ 。栽培过程中的耕作是葡萄园地面管理 中最重要的一项管理措施, 对GHG的排放和平衡具 有重要作用。耕作过程中使用拖拉机等设备燃烧化 石燃料会产生 $\mathrm{CO}_{2}$ 。研究发现, 在葡萄园中使用 $1 \mathrm{~L}$ 柴油产生3.15 kg CO , 使用 $1 \mathrm{~L}$ 汽油产生 $2.78 \mathrm{~kg}$ $\mathrm{CO}_{2}$ (Carlisle et al., 2006)。

不同品种葡萄园 $\mathrm{CO}_{2}$ 排放量不同。Steenwerth和 Belina (2010)研究赤霞珠葡萄园碳排放量, 发现每 年 $\mathrm{CO}_{2}$ 的排放范围为 $1.1-1.5 \mathrm{t} \cdot \mathrm{hm}^{-2}$, 这一数值高于 Carlisle等(2006)所研究的美乐葡萄园。管理方式也 会影响葡萄园 $\mathrm{CO}_{2}$ 排放量, 与传统葡萄园相比, 有 机葡萄园的 $\mathrm{CO}_{2}$ 排放量要低得多。研究者从农业系 统的角度, 研究常规葡萄园和有机葡萄园的 $\mathrm{CO}_{2}$ 排 放量, 发现有机葡萄园的GHG排放量明显低于常规 葡萄园(Kavargiris et al., 2009)。

此外, 葡萄园栽培过程中产生的主要 $\mathrm{GHG}$ 为 $\mathrm{N}_{2} \mathrm{O}$ (Nistor et al., 2018), 如果葡萄园中施用过量的
氮肥(硝酸盐、氨、绿肥、果渣、修剪枝条和覆盖物), 或在错误的时间(高湿度)和地点(压实土壤)施用氮 肥, 可通过硝化和反硝化作用转化为 $\mathrm{N}_{2} \mathrm{O} 、 \mathrm{~N}_{2}$ 和 $\mathrm{NH}_{3}$ (Bremner, 1997; Mosier et al., 2005)。研究发现, 有机 质分解是氮的主要来源, $\mathrm{N}_{2} \mathrm{O}$ 的排放取决于葡萄园 的管理方式, 包括土壤类型、肥料用量和土壤含水 量(Hawk \& Martinson, 2007), 因此可通过控制葡萄 园管理措施来减少氮排放。

\section{2 碳减排策略}

在陆地的养分循环中, 排放到大气中的碳有一 半来自表层土壤的异氧呼吸, 田间管理引起的土壤 变化会强烈影响碳储存, 特别是耕作管理显著影响 碳储存(Chan et al., 2011)。

在葡萄栽培过程中, 通过耕作、施肥、收割、 灌溉、电力、天然气、运输和葡萄酒营销等土地和 作物管理可以减缓 $\mathrm{CO}_{2}$ 的排放。在过去几十年里, 除 了免耕之外, 覆盖一直作为减少葡萄园 $\mathrm{CO}_{2}$ 排放和 提高土壤肥力的最有效方法。

\subsection{1 免耕}

免耕将有机物储存到土壤中会导致碳封存 (Helgason et al., 2010), 免耕处理增加土壤中碳储量 和封存量, 是减少葡萄园碳排放的有效方法。研究 发现, 耕作加快了土壤有机质的分解, 产生了更多 $\mathrm{CO}_{2}$ (Yu et al., 2017)。然而, 也有研究发现, 减少耕 作, SOC会减少。与传统耕作过程中使用多台拖拉机 和设备相比, 少耕处理SOC 储存量较少(Sanderman \& Baldock, 2010), 可能原因为减少耕作使土壤微生 物丰度和活动增强，矿化作用造成SOC减少。

耕作导致土壤温度升高引起有机物分解加快, 同时耕作过程中使用拖拉机等设备会燃烧化石燃料, 这些是葡萄园 $\mathrm{CO}_{2}$ 排放的主要来源(Mangalassery et al., 2014)。有研究发现, 葡萄园生态系统的不同组 成部分(土壤、植被和木质生物量等), 能够有效抵消 化石燃料燃烧所排放的碳(Paradelo et al., 2011)。当 然, 通过最小化耕作减少拖拉机的使用, 减少燃料 消耗是减少 $\mathrm{CO}_{2}$ 排放的最常用措施(McGourty et al., 2008)。耕作管理和燃料使用被认为是葡萄园中提高 土壤 $\mathrm{C}$ 储量和减少碳排放的主要控制因素(Garland et al., 2011; Petersen et al., 2011)。一方面频繁的耕作 需要更多的燃料, 排放大量的碳, 同时也限制耕作 层土壤碳的封存(Wolff et al., 2018); 另一方面, 耕 作管理引起的土壤变化会强烈影响葡萄园生态系统 
中的碳循环, 轻度耕作会造成对土壤的干扰, 分解 土壤聚集体, 使之前受保护的土壤有机质暴露于微 生物的分解之下, 导致土壤中的碳因为氧化分解而 损失。所以, 耕作管理对葡萄园碳汇功能十分重要。

\subsection{2 覆盖}

葡萄园生态系统中已经尝试了许多固碳方法, 如覆盖、有机改良、作物残茬、少耕或免耕、改良轮 作和复种。无论采用何种方法, SOC变化缓慢, 对于 可检测到的变化, 长期的实验是必要的 (Smith, 2004)。在短期2-3年的研究中, 覆盖草本植物的固 碳率高于间作大麦(Hordeum vulgare)(Peregrina et al., 2010)。在过去的几十年里, 覆盖上作物用来增 加土壤的肥力, 改善土壤结构, 提高碳封存(Delgado et al., 2007; Dobrei et al., 2015), 也可以更好地控制 疾病和害虫(Basche et al., 2014)。

覆盖一年生作物显著提高土壤碳含量。葡萄园 中覆盖一年生作物, 提升的碳含量为 $68 \mathrm{~g} \cdot \mathrm{m}^{-2}$ (Kroodsma \& Field, 2006)。Steenwerth和Belina (2008) 采用两种一年生作物组合的覆盖方法, 在霞多丽葡 萄园经过 5 年的研究, 发现在0-20 $\mathrm{cm}$ 深的土壤中碳 固定量分别为 $(9.45 \pm 0.034) 、(10.98 \pm 0.030) \mathrm{mg} \cdot \mathrm{kg}^{-1}$, 均显著高于裸露土壤碳固定量 $(7.18 \pm 0.18) \mathrm{mg} \cdot \mathrm{kg}^{-1}$ 。 有研究发现, 葡萄园中覆盖多年生作物可以在 5 年 内增加土壤碳含量, 比裸露土壤增加 1.4 倍(Celette et al., 2009), 究其原因是多年生作物的根系深、根 系生物量高, 显著增加土壤中碳含量(Vendrame et al., 2019)。覆盖多年生草本植物对土壤碳含量也有正向 影响, 其原因为多年草本植物根系生物量与叶生物 量的比值更高, 分泌到土壤更多的碳(Sanderman \& Baldock, 2010)。如, Peregrina等(2014)在西班牙东北 部的丹魄(Vitis vinifera 'Tempranillo')葡萄园进行覆 盖草本植物的研究, 发现覆盖波斯三叶草(Trifolium resupinatum), SOC增加量为 $1.19 \mathrm{t} \cdot \mathrm{hm}^{-2}$ 。此外, 葡萄 园中覆盖作物与传统耕作方式相结合可以减少化肥 的使用, 提高土壤质量和碳含量(Sainju et al., 2002; Baumgartner et al., 2008)。

葡萄园覆盖豆科作物不仅有助于碳封存, 也可 以更好地保持土壤中的氮, 降低葡萄种植行内土壤 淋溶作用。豆科作物增加土壤中氮含量, 在一定程 度上减少了无机肥的使用(Basche et al., 2014), 与 此同时, 豆科作物所增加的高水平的氮肥会增加 $\mathrm{N}_{2} \mathrm{O}$ 的排放。可通过行间间作黑麦草(Lolium per-
enne)、野生稻(Oryza rufipogon)等多年生草本植物 限制硝酸盐的浸出和 $\mathrm{N}_{2} \mathrm{O}$ 排放 (Feyereisen et al., 2006), 由于多年生草本植物可以有效利用土壤中 的有效氮。然而, 在葡萄园中覆盖豆科作物的负面 影响可能与葡萄竞争营养物质有关, 也可能与通过 侵蚀作用造成土壤有机质减少有关。有研究发现, 覆盖豆科作物对碳汇有负面影响(Chan et al., 2011)。 覆盖豆科作物对葡萄园的碳汇功能尚存在争议, 还 需进一步的研究。

除了覆盖之外, 有机葡萄栽培中通过创建有益 昆虫的栖息地、保持葡萄树平衡和树冠综合管理来 控制GHG排放、杂草和害虫, 减缓有机物分解, 增 加土壤碳库中的碳含量(Basche et al., 2014)。

\section{4 展望}

综上所述, 葡萄园生态系统碳汇和碳循环等相 关研究已经取得了一定的成果。纵观国内外研究, 葡萄园的碳汇功能已被广泛认可。然而, 葡萄园生 态系统碳汇和碳循环研究尚有如下问题亟待解决:

1)温室效应影响全球气候变化, 同时也影响到 陆地植被的养分供应, 进而对陆地生态系统的分 布、组成、结构和功能产生深刻的影响 (Smith \& Wigley, 2000)。未来研究工作应积极探索葡萄园生 态系统碳循环机制，摸清整个循环涉及的物理、化 学、生物过程以及影响碳吸收、转移和支出的因素, 探讨全球气候变化条件下葡萄园对未来人类生存环 境的反馈影响。

2)葡萄生长的最适温度为 $16-22{ }^{\circ} \mathrm{C}$, 最适气孔 导度为 $0.02 \mathrm{~m} \cdot \mathrm{s}^{-1}$, 研究发现温度、大气 $\mathrm{CO}_{2}$ 密度、 饱和水气压、冠层导度和净辐射等非生物因素影响 葡萄园NEE (Li et al., 2013)。今后研究可通过不同时 间尺度, 分析葡萄园NEE对各因子的响应规律, 进 一步明确葡萄园生态系统碳平衡。

3)葡萄园生态系统属于源还是汇取决于碳输入 与碳释放之间的平衡, 虽然碳通量的研究可以提供 葡萄园生态系统 $\mathrm{CO}_{2}$ 动态变化, 但是到目前为止, 研究还没有考虑到在葡萄园建园过程中土壤耕作产 生的 $\mathrm{CO}_{2}$, 或者在葡萄园整体移除过程中由于耕作 产生的 $\mathrm{CO}_{2}$ 排放, 以及葡萄植株多年生器官(主干和 主蔓)的燃烧或分解产生的 $\mathrm{CO}_{2}$ 。因此，未来关于葡 萄园生态系统碳汇的研究要进行系统、全面的碳动 态研究。 
4)进一步完善探讨碳循环与氮循环、水循环耦 合关系的研究。应分析各个区域不同种植模式条件 下, 葡萄园的固碳现状与潜力, 变定性描述为定量 研究; 从不同时间尺度上研究影响葡萄园生态系统 固碳能力的气候、土壤、种植制度等综合因素, 阐 述各因素对碳循环的影响。重点研究葡萄园生态系 统中碳循环与氮循环、水循环的耦合关系, 分析不 同氮、水条件下碳的固定情况, 以及土壤微生物在 葡萄园生态系统碳循环与氮循环、水循环的耦合关 系的机理研究。

5)综合已知有关陆地生态系统碳循环的基本生 态学理论, 可以详细、系统地构建碳循环模型, 实现 对不同时间、不同空间乃至全球范围上碳收支的评 价, 是解决大尺度区域碳汇研究十分有效的技术手 段(Guo et al., 2014)。所以, 今后对葡萄园生态系统 碳循环与碳交换量的评价过程的研究, 碳循环模型 的构建必不可少, 常用的碳循环模型有: 温度模 型、 $Q_{10}$ 模型、水分温度模型和植被与大气相互作用 模型(AVIM模型)。利用碳循环模型来估算不同的管 理条件下葡萄园生态系统中碳的再分配模式; 利用 碳循环模型预测葡萄园生态系统碳的动态变化, 实 现对葡萄园土壤肥力的最大化利用, 为减少 $\mathrm{GHG}$ 排 放提供可靠理论依据。

\section{参考文献}

Agnelli A, Bol R, Trumbore SE, Dixon L, Cocco S, Corti G (2014). Carbon and nitrogen in soil and vine roots in harrowed and grass-covered vineyards. Agriculture, Ecosystems \& Environment, 193, 70-82.

Basche AD, Miguez FE, Kaspar TC, Castellano MJ (2014). Do cover crops increase or decrease nitrous oxide emissions? A meta-analysis. Journal of Soil and Water Conservation, 69, 471-482.

Bates TR, Dunst RM, Joy P (2002). Seasonal dry matter, starch, and nutrient distribution in 'concord' grapevine roots. HortScience, 37, 313-316.

Bauerle TL, Smart DR, Bauerle WL, Stockert C, Eissenstat DM (2008). Root foraging in response to heterogeneous soil moisture in two grapevines that differ in potential growth rate. New Phytologist, 179, 857-866.

Baumgartner K, Steenwerth KL, Veilleux L (2008). Cover-crop systems affect weed communities in a California vineyard. Weed Science, 56, 596-605.

Bosco S, Di Bene C, Galli M, Remorini D, Massai R, Bonari E (2011). Greenhouse gas emissions in the agricultural phase of wine production in the Maremma rural district in Tuscany, Italy. Italian Journal of Agronomy, 6, e15. DOI: 10.4081/ija.2011.e15.

Bremner JM (1997). Sources of nitrous oxide in soils. Nutrient Cycling in Agroecosystems, 49, 7-16.

Brunori E, Farina R, Biasi R (2016). Sustainable viticulture: the carbon-sink function of the vineyard agro-ecosystem. Agriculture, Ecosystems \& Environment, 223, 10-21.

Buermann W, Lintner BR, Koven CD, Angert A, Pinzon JE, Tucker CJ, Fung IY (2007). The changing carbon cycle at Mauna Loa Observatory. Proceedings of the National Academy of Sciences of the United States of America, 104, 4249-4254.

Carlisle EA, Steenwerth KL, Smart DR (2006). Effects of land use on soil respiration: conversion of oak woodlands to vineyards. Journal of Environmental Quality, 35, 13961404.

Celette F, Findeling A, Gary C (2009). Competition for nitrogen in an unfertilized intercropping system: the case of an association of grapevine and grass cover in a Mediterranean climate. European Journal of Agronomy, 30, 41-51.

Celette F, Gaudin R, Gary C (2008). Spatial and temporal changes to the water regime of a Mediterranean vineyard due to the adoption of cover cropping. European Journal of Agronomy, 29, 153-162.

Chan KY, Conyers MK, Li GD, Helyar KR, Poile G, Oates A, Barchia IM (2011). Soil carbon dynamics under different cropping and pasture management in temperate Australia: results of three long-term experiments. Soil Research, 49, 320-328.

Chen SC, Martin MP, Saby NPA, Walter C, Angers DA, Arrouays D (2018). Fine resolution map of top- and subsoil carbon sequestration potential in France. Science of the Total Environment, 630, 389-400.

Chiarawipa R, Wang Y, Zhang XZ, Han ZH (2013). Growing season carbon dynamics and stocks in relation to vine ages under a vineyard agroecosystem in Northern China. American Journal of Plant Physiology, 8, 1-16.

Chiriacò MV, Belli C, Chiti T, Trotta C, Sabbatini S (2019). The potential carbon neutrality of sustainable viticulture showed through a comprehensive assessment of the greenhouse gas (GHG) budget of wine production. Journal of Cleaner Production, 225, 435-450.

Colman T, Päster P (2007). Red, white and 'green': the cost of carbon in the global wine trade. American Association of Wine Economists, 9, 1-19.

Delgado JA, Dillon MA, Sparks RT, Essah SYC (2007). A decade of advances in cover crops: cover crops with limited irrigation can increase yields, crop quality, and nutrient and water use efficiencies while protecting the environment. Journal of Soil and Water Conservation, 62, 110-117.

Deurer M, Müller K, Kim I, Huh KY, Young I, Jun GI, Clothier

www.plant-ecology.com 
BE (2012). Can minor compaction increase soil carbon sequestration? A case study in a soil under a wheel-track in an orchard. Geoderma, 183-184, 74-79.

Dobrei A, Nistor E, Sala F, Dobrei A (2015). Tillage practices in the context of climate change and a sustainable viticulture. Notulae Scientia Biologicae, 7, 500-504.

DuPont ST, Culman SW, Ferris H, Buckley DH, Glover JD (2010). No-tillage conversion of harvested perennial grassland to annual cropland reduces root biomass, decreases active carbon stocks, and impacts soil biota. Agriculture, Ecosystems \& Environment, 137, 25-32.

Eldon J, Gershenson A (2015). Effects of cultivation and alternative vineyard management practices on soil carbon storage in diverse Mediterranean landscapes: a review of the literature. Agroecology and Sustainable Food Systems, 39, 516-550.

Fang YL, Hui ZM, Chen J, He JL, Zhang ZW (2006). Effects of water stress on photosynthetic properties of grapevine. Agricultural Research in the Arid Areas, 24, 135-138. [房玉 林, 惠竹梅, 陈洁, 何建林, 张振文 (2006). 水分胁迫 对葡萄光合特性的影响. 干旱地区农业研究, 24, 135138.]

Feyereisen GW, Wilson BN, Sands GR, Strock JS, Porter PM (2006). Potential for a rye cover crop to reduce nitrate loss in southwestern Minnesota. Agronomy Journal, 98, 14161426.

Fidelibus MW (2014). Grapevine cultivars, trellis systems, and mechanization of the California raisin industry. HortTechnology, 24, 285-289.

Fusi A, Guidetti R, Benedetto G (2014). Delving into the environmental aspect of a Sardinian white wine: from partial to total life cycle assessment. Science of the Total Environment, 472, 989-1000.

Garland GM, Suddick E, Burger M, Horwath WR, Six J (2011). Direct $\mathrm{N}_{2} \mathrm{O}$ emissions following transition from conventional till to no-till in a cover cropped Mediterranean vineyard (Vitis vinifera). Agriculture, Ecosystems \& Environment, 144, 423-428.

Goosse H (2010). Carbon cycle: degrees of climate feedback. Nature, 463, 438-439.

Govaerts B, Verhulst N, Castellanos-Navarrete A, Sayre KD, Dixon J, Dendooven L (2009). Conservation agriculture and soil carbon sequestration: between myth and farmer reality. Critical Reviews in Plant Sciences, 28, 97-122.

Guo WH, Gao Y (2013). The variation of vineyard net $\mathrm{CO}_{2}$ exchange under different conditions in northwest arid. Journal of Irrigation and Drainage, 32, 107-109, 136. [郭 维华, 高云 (2013). 西北旱区葡萄园 $\mathrm{CO}_{2}$ 净交换量变化 规律. 灌溉排水学报, 32, 107-109, 136.]

Guo WH, Kang SZ, Li FS, Li SE (2014). Variation of NEE and its affecting factors in a vineyard of arid region of northwest China. Atmospheric Environment, 84, 349-354.
Hawk J, Martinson TE (2007). Sustainable viticulture: optimizing nitrogen use in vineyards. New York Fruit Quarterly, 15, 25-29.

Helgason BL, Walley FL, Germida JJ (2010). No-till soil management increases microbial biomass and alters community profiles in soil aggregates. Applied Soil Ecology, 46, 390-397.

Houghton RA, Goodale CL (2004). Effects of land-use change on the carbon balance of terrestrial ecosystems. Geophysical Monograph Series, 153, 85-98.

Janssens IA, Freiebauer A, Ciais P, Smith P, Nabuurs GJ, Folberth G, Schlamadinger B, Hutjes RWA, Ceulemans R, Schulze ED, Valentini R, Dolman AJ (2003). Europe's terrestrial biosphere absorbs 7 to $12 \%$ of European anthropogenic $\mathrm{CO}_{2}$ emissions. Science, 300, 1538-1542.

Jastrow JD, Amonette JE, Bailey VL (2007). Mechanisms controlling soil carbon turnover and their potential application for enhancing carbon sequestration. Climatic Change, 80, $5-23$.

Kavargiris SE, Mamolos AP, Tsatsarelis CA, Nikolaidou AE, Kalburtji KL (2009). Energy resources' utilization in organic and conventional vineyards: energy flow, greenhouse gas emissions and biofuel production. Biomass and Bioenergy, 33, 1239-1250.

Kroodsma DA, Field CB (2006). Carbon sequestration in California agriculture, 1980-2000. Ecological Applications, 16, 1975-1985.

Kuyah S, Dietz J, Muthuri C, Jamnadass R, Mwangi P, Coe R, Neufeldt H (2012). Allometric equations for estimating biomass in agricultural landscapes: II. Belowground biomass. Agriculture, Ecosystems \& Environment, 158, 225-234.

Lal R (2004). Soil carbon sequestration impacts on global climate change and food security. Science, 304, 1623-1627.

Lejon DPH, Sebastia J, Lamy I, Chaussod R, Ranjard L (2007). Relationships between soil organic status and microbial community density and genetic structure in two agricultural soils submitted to various types of organic management. Microbial Ecology, 53, 650-663.

Li SE, Kang SZ, Zhang L, Li FS, Hao XM, Ortega-Farias S, Guo WH, Ji SS, Wang JT, Jiang XL (2013). Quantifying the combined effects of climatic, crop and soil factors on surface resistance in a maize field. Journal of Hydrology, 489, 124-134.

Liguori G, Gugliuzza G, Inglese P (2009). Evaluating carbon fluxes in orange orchards in relation to planting density. The Journal of Agricultural Science, 147, 637-645.

Longbottom ML, Petrie PR (2015). Role of vineyard practices in generating and mitigating greenhouse gas emissions. Australian Journal of Grape and Wine Research, 21, 522536.

Ludwig B, Geisseler D, Michel K, Joergensen RG, Schulz E, Merbach I, Raupp J, Rauber R, Hu K, Niu L, Liu X (2011). 
Effects of fertilization and soil management on crop yields and carbon stabilization in soils. A review. Agronomy for Sustainable Development, 31, 361-372.

Luo ZK, Wang EL, Sun OJX (2010). Soil carbon change and its responses to agricultural practices in Australian agroecosystems: a review and synthesis. Geoderma, 155, 211-223.

Mangalassery S, Sjögersten S, Sparkes DL, Sturrock CJ, Craigon J, Mooney SJ (2014). To what extent can zero tillage lead to a reduction in greenhouse gas emissions from temperate soils? Scientific Reports, 4, 4586. DOI: 10.1038/ srep04586.

Marras S, Masia S, Duce P, Spano D, Sirca C (2015). Carbon footprint assessment on a mature vineyard. Agricultural and Forest Meteorology, 214-215, 350-356.

McGourty G, Nosera J, Tylicki S, Toth A (2008). Self-reseeding annual legumes evaluated as cover crops for untilled vineyards. California Agriculture, 62, 191-194.

Morandé JA, Stockert CM, Liles GC, Williams JN, Smart DR, Viers JH (2017). From berries to blocks: carbon stock quantification of a California vineyard. Carbon Balance and Management, 12, 5-17.

Morlat R, Chaussod R (2008). Long-term additions of organic amendments in a Loire Valley vineyard. I. Effects on properties of a calcareous sandy soil. American Journal of Enology and Viticulture, 59, 353-363.

Mosier AR, Halvorson AD, Peterson GA, Robertson GP, Sher$\operatorname{rod} L$ (2005). Measurement of net global warming potential in three agroecosystems. Nutrient Cycling in Agroecosystems, 72, 67-76.

Nendel C, Kersebaum KC (2004). A simple model approach to simulate nitrogen dynamics in vineyard soils. Ecological Modelling, 177, 1-15.

Nistor E, Dobrei AG, Dobrei A, Camen D, Sala F, Prundeanu H (2018). $\mathrm{N}_{2} \mathrm{O}, \mathrm{CO}_{2}$, production, and $\mathrm{C}$ sequestration in vineyards: a review. Water Air \& Soil Pollution, 229, 112122.

Novara A, Gristina L, Kuzyakov Y, Schillaci C, Laudicina VA, La Mantia T (2013). Turnover and availability of soil organic carbon under different Mediterranean land-uses as estimated by ${ }^{13} \mathrm{C}$ natural abundance. European Journal of Soil Science, 64, 466-475.

Novara A, Gristina L, Saladino SS, Santoro A, Cerdà A (2011). Soil erosion assessment on tillage and alternative soil managements in a Sicilian vineyard. Soil \& Tillage Research, 117, 140-147.

Novara A, Minacapilli M, Santoro A, Rodrigo-Comino J, Carrubba A, Sarno M, Venezia G, Gristina L (2019). Real cover crops contribution to soil organic carbon sequestration in sloping vineyard. Science of the Total Environment, 652, 300-306.

Paradelo R, Moldes AB, Barral MT (2011). Carbon and nitrogen mineralization in a vineyard soil amended with grape marc vermicompost. Waste Management \& Research, 29, $1177-1184$.

Peregrina F, Larrieta C, Ibáñez S, García-Escudero E (2010). Labile organic matter, aggregates, and stratification ratios in a semiarid vineyard with cover crops. Soil Science Society of America Journal, 74, 2120-2130.

Peregrina F, Pérez-Álvarez EP, García-Escudero E (2014). The short term influence of aboveground biomass cover crops on $\mathrm{C}$ sequestration and $\beta$-glucosidase in a vineyard ground under semiarid conditions. Spanish Journal of Agricultural Research, 12, 1000-1007.

Petersen SO, Mutegi JK, Hansen EM, Munkholm LJ (2011). Tillage effects on $\mathrm{N}_{2} \mathrm{O}$ emissions as influenced by a winter cover crop. Soil Biology \& Biochemistry, 43, 1509-1517.

Pizzigallo ACI, Granai C, Borsa S (2008). The joint use of LCA and emergy evaluation for the analysis of two Italian wine farms. Journal of Environmental Management, 86, 396-406.

Post WM, Kwon KC (2000). Soil carbon sequestration and land-use change: processes and potential. Global Change Biology, 6, 317-327.

Powlson DS, Whitmore AP, Goulding KWT (2011). Soil carbon sequestration to mitigate climate change: a critical re-examination to identify the true and the false. European Journal of Soil Science, 62, 42-55.

Rugani B, Vázquez-Rowe I, Benedetto G, Benetto E (2013). A comprehensive review of carbon footprint analysis as an extended environmental indicator in the wine sector. Journal of Cleaner Production, 54, 61-77.

Sainju UM, Singh BP, Whitehead WF (2002). Long-term effects of tillage, cover crops, and nitrogen fertilization on organic carbon and nitrogen concentrations in sandy loam soils in Georgia, USA. Soil and Tillage Research, 63, 167-179.

Sanderman J, Baldock JA (2010). Accounting for soil carbon sequestration in national inventories: a soil scientist's perspective. Environmental Research Letters, 5, 034003. DOI: 10.1088/1748-9326/5/3/034003.

Smith LC, MacDonald GM, Velichko AA, Beilman DW, Borisova OK, Frey KE, Kremenetski KV, Sheng Y (2004). Siberian peatlands a net carbon sink and global methane source since the early Holocene. Science, 303, 353-356.

Smith P (2004). How long before a change in soil organic carbon can be detected? Global Change Biology, 10, 18781883.

Smith SJ, Wigley ML (2000). Global warming potentials: 1. Climatic implications of emissions reductions. Climatic Change, 44, 445-457.

Soosay C, Fearne A, Dent B (2012). Sustainable value chain analysis-A case study of Oxford Landing from "vine to dine". Supply Chain Management, 17, 68-77.

Steenwerth KL, Belina KM (2008). Cover crops enhance soil organic matter, carbon dynamics and microbiological

www.plant-ecology.com 
function in a vineyard agroecosystem. Applied Soil Ecology, 40, 359-369.

Steenwerth KL, Belina KM (2010). Vineyard weed management practices influence nitrate leaching and nitrous oxide emissions. Agriculture, Ecosystems \& Environment, 138, 127-131.

Tesic D, Keller M, Hutton R (2007). Influence of vineyard floor management practices on grapevine vegetative growth, yield, and fruit composition. American Journal of Enology and Viticulture, 58, 1-11.

Tezza L, Vendrame N, Pitacco A (2019). Disentangling the carbon budget of a vineyard: the role of soil management. Agriculture, Ecosystems \& Environment, 272, 52-62.

Tian Y, Chen GM, Li JF, Xiang XY, Liu Y, Li HY (2018). Present development of grape industry in the world. Chinese Journal of Tropical Agriculture, 38(6), 96-105. [田野, 陈 冠铭, 李家芬, 向雄鹰, 刘扬, 李宏杨 (2018). 世界葡 萄产业发展现状. 热带农业科学, 38(6), 96-105.]

Vendrame N, Tezza L, Pitacco A (2019). Study of the carbon budget of a temperate-climate vineyard: inter-annual variability of $\mathrm{CO}_{2}$ flux. American Journal of Enology and Viticulture, 70, 34-41.

Walther GR, Post E, Convey P, Menzel A, Parmesan C, Beebee TJC, Fromentin JM, Hoegh-Guldberg O, Bairlein F (2002). Ecological responses to recent climate change. Nature, 416, 389-395.

Wang L, Li H, Wang H (2017). Climatic regionalization of grape in China II: wine grape varieties regionalization. Chinese Science Bulletin, 62, 1539-1554. [王蕾, 李华, 王华 (2017). 中国葡萄气候区划II: 酿酒葡萄品种区域化. 科学通报, $62,1539-1554$.

West TO, Marland G (2002). A synthesis of carbon sequestration, carbon emissions, and net carbon flux in agriculture: comparing tillage practices in the United States. Agricul- ture, Ecosystems \& Environment, 91, 217-232.

Wightwick AM, Reichman SM, Menzies NW, Allinson G (2013). Industry wide risk assessment: a case study of $\mathrm{Cu}$ in Australian vineyard soils. Water Air \& Soil Pollution, 224, 1702. DOI: 10.1007/s11270-013-1702-2.

Williams JN, Hollander AD, O'Geen AT, Thrupp LA, Hanifin R, Steenwerth K, McGourty G, Jackson LE (2011). Assessment of carbon in woody plants and soil across a vineyard-woodland landscape. Carbon Balance and Management, 6, 11. DOI: 10.1186/1750-0680-6-11.

Wolff MW, Alsina MM, Armstrong-Stockert C, Khalsa SDS, Smart DR (2018). Minimum tillage of a cover crop lowers net GWP and sequesters soil carbon in a California vineyard. Soil and Tillage Research, 175, 244-254.

Yan QD, Su PX (2005). Photosynthetic characteristics of grapvine leaves under different soil moistures. Acta Botanica Boreali-Occidentalia Sinica, 25, 1601-1606. [严巧娣, 苏 培尔 (2005). 不同土壤水分条件下葡萄叶片光合特性 的比较. 西北植物学报, 25, 1601-1606.]

Yang JF, Yang XN, Wang JH, Duan YM, Qi XN, Zhang LS (2018). Characteristics of $\mathrm{CO}_{2}$ flux in a mature apple (Malus demestica) orchard ecosystem on the Loess Plateau. Environmental Science, 39, 2339-2350. [杨剑锋, 杨小妮, 王 俊花, 段宇敏, 祁香宁, 张林森 (2018). 黄土高原成龄 苹果园生态系统 $\mathrm{CO}_{2}$ 通量特征. 环境科学, 39, 23392350.]

Yu OT, Greenhut RF, O'Geen AT, Mackey B, Horwath WR, Steenwerth KL (2017). Precipitation events and management practices affect greenhouse gas emissions from vineyards in a Mediterranean climate. Soil Science Society of America Journal, 81, 138-152.

责任编委: 储诚进 编辑: 赵 航 